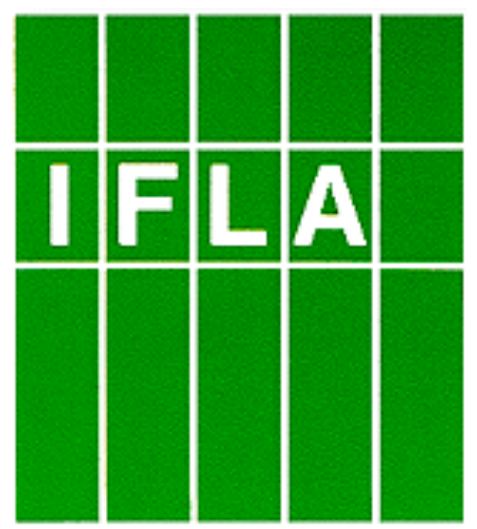

International Federation of Library Associations and Institutions

Functional Requirements for Subject Authority Data (FRSAD) A Conceptual Model

IFLA Working Group on the

Functional Requirements for Subject Authority Records (FRSAR)

Editors: Marcia Lei Zeng, Maja Žumer, Athena Salaba

Approved by the Standing Committee of the IFLA Section on Classification and Indexing

June 2010 


\section{CONTENTS}

MEMBERS OF THE IFLA WORKING GROUP ON THE FUNCTIONAL REQUIREMENTS FOR SUBJECT AUTHORITY RECORDS (FRSAR) …….............................................................. 4

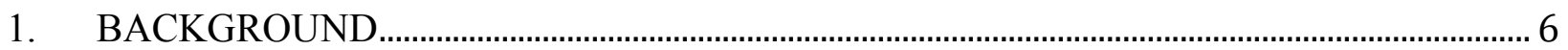

2. PURPOSE AND SCOPE

2.1 PURPOSE

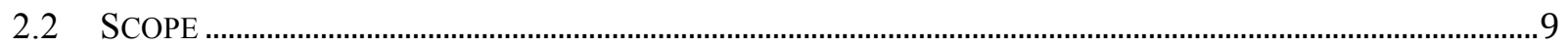

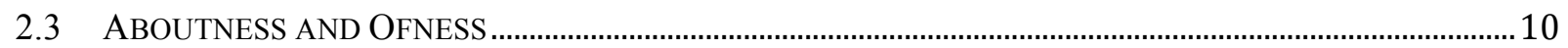

2.4 METHOD

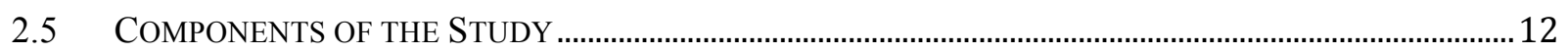

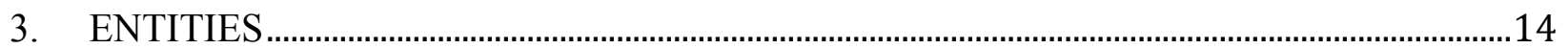

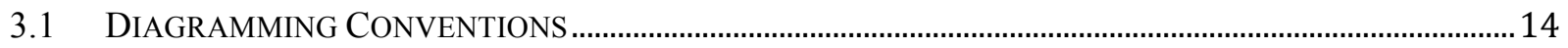

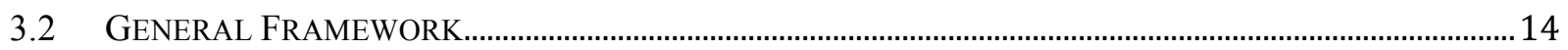

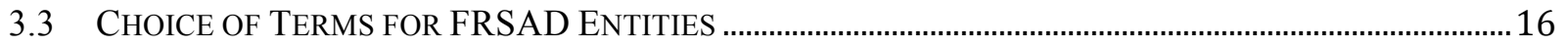

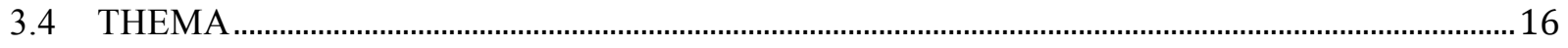

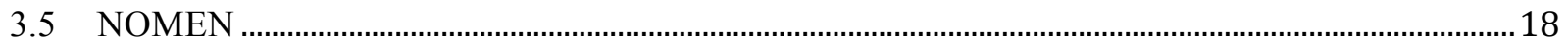

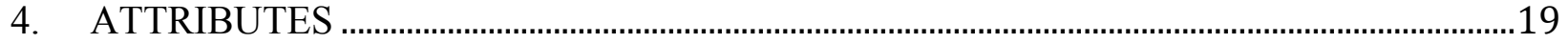

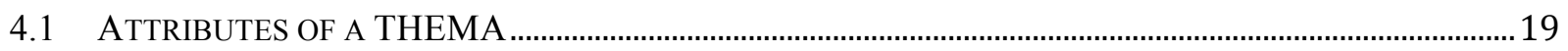

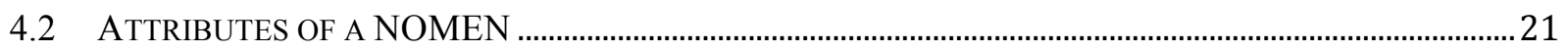

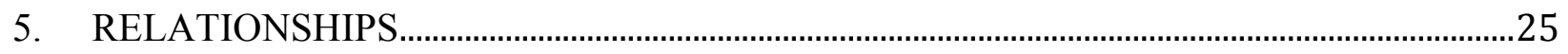

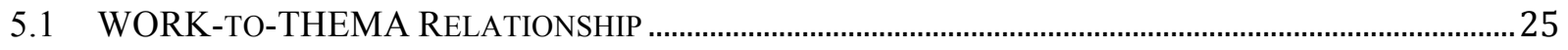

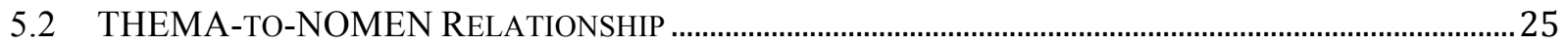

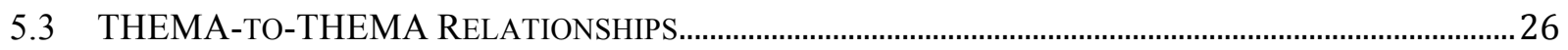

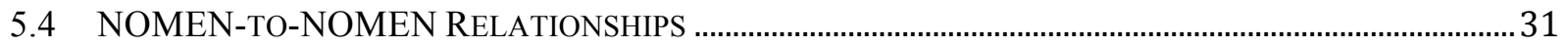

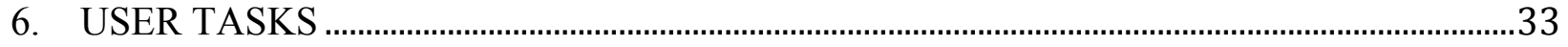

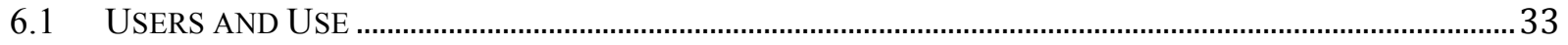

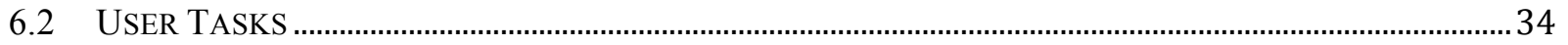

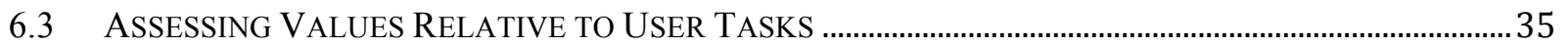

6.4 MAPPING OF ATTRIBUTES, RELATIONSHIPS, AND USER TASKS............................................................ 37

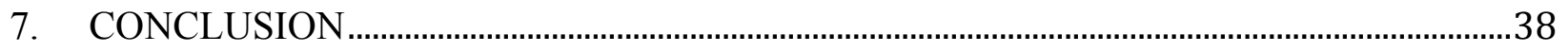

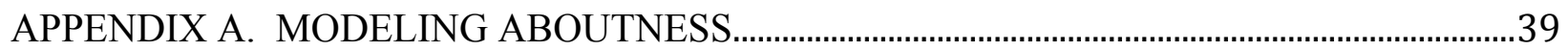

A.1 SUBJECT RELATIONSHIP AND GROUP 3 ENTITIES INTRODUCED IN FRBR .........................................39

A.2 POSSIBLE APPROACHES TO THE MODEL OF ABOUTNESS ……............................................................ 40

APPENDIX B. RELATIONSHIP OF FRSAD WITH FRBR AND FRAD .........................................45

B.1 RELATIONSHIP OF FRSAD WITH FRBR

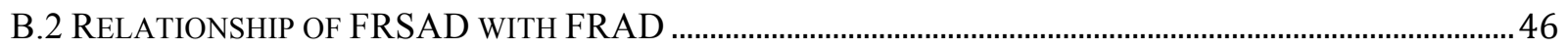

APPENDIX C. FRSAD MODEL AND OTHER MODELS …..........................................................48

C.1 THE IMPORTANCE OF THE THEMA-NOMEN MODEL ….......................................................................... 48

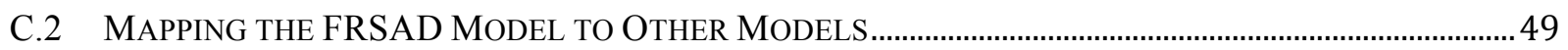

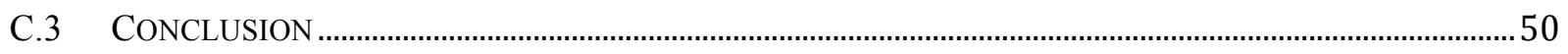

APPENDIX D. EXAMPLES FROM SUBJECT AUTHORITY SYSTEMS .................................51

D.1 EXISTING MODELS OF THEMA TYPES ........................................................................................ 51

D.2 THEMA-THEMA RELATIONSHIPS PRESENTED IN SUBJECT AUTHORITY DATA..............................55 
D.3 SAME THEMA REPRESENTED BY NOMENS FROM DIFFERENT SCHEMES .....................................68

D.4 EXAMPLES OF DiSPlay RECORDS FROM CONTROLLED VOCABULARIES OR SUBJECT AUTHORITY FILES 68

REFERENCES . 


\title{
MEMBERS OF THE IFLA WORKING GROUP ON THE FUNCTIONAL REQUIREMENTS FOR SUBJECT AUTHORITY RECORDS (FRSAR)
}

\author{
Working Group
}

Leda Bultrini

ARPA Lazio (Regional Environment Protection Agency), Italy

Lois Mai Chan

University of Kentucky, USA

Jonathan Furner

University of California Los Angeles, USA

Edward O’Neill

OCLC, USA

Gerhard Riesthuis

University of Amsterdam, The Netherlands

Athena Salaba (Co-Chair and Secretary)

Kent State University, USA

Diane Vizine-Goetz

OCLC, USA

Ekaterina Zaytseva

Russian National Public Library for Science and Technology, Russia

Marcia Lei Zeng (Chair)

Kent State University, USA

Maja Žumer (Co-Chair)

University of Ljubljana, Slovenia 


\section{Advisory Group}

Victoria Francu (2005-06)

Central University, Bucharest, Romania

Hemalata Iyer (2008)

Albany State University of New York, USA

Dorothy McGarry

University of California, Los Angeles, USA

David Miller

Curry College, USA

Päivi Pekkarinen

National Library of Health Sciences, Finland

Barbara Tillett

Library of Congress, USA

This document was prepared by:

Marcia Lei Zeng, Maja Žumer, Athena Salaba, Jonathan Furner, Lois Mai Chan, Ed O’Neill, Diane Vizine-Goetz 


\section{BACKGROUND}

The IFLA Study Group on the Functional Requirements for Bibliographic Records (FRBR) developed a conceptual model showing the entities and relationships of the bibliographic universe in 1997. The purpose of the FRBR model is to identify the functional requirements of information in bibliographic records to facilitate the specified user tasks. ${ }^{1}$ The basic entities of the FRBR model are the result of a logical analysis of the data typically represented in bibliographic records. The entities are divided into three groups:

Group 1 entities are defined as the products of intellectual or artistic endeavours that are named or described in bibliographic records: work, expression, manifestation, and item.

Group 2 entities are those responsible for the intellectual or artistic content, the physical production and dissemination, or the custodianship of the Group 1 entities: person, corporate body, and family. ${ }^{2}$.

Group 3 entities represent an additional set of entities that serve as the subjects of works: concept, object, event, and place.

The FRBR final report presents the entity-relationship model, identifies entities and their attributes, and defines relationships among entities. Although in the FRBR model the entities of all three groups are defined, the main focus is on the first group. The developers of FRBR envisioned that its extensions would cover the additional data that are normally recorded in authority records.

The Working Group on Functional Requirements and Numbering of Authority Records (FRANAR) was established in April 1999. It was charged to continue the work of FRBR by developing a conceptual model for entities described in authority records. Authority data in the context of their work is defined as "the aggregate of information about a person, family, corporate body, or work whose name is used as the basis for a controlled access point for bibliographic citations or records in a library catalogue or bibliographic file"3. The primary purpose of the Functional Requirements for Authority Data (FRAD) conceptual model is "to provide a framework for the analysis of functional requirements for the kind of authority data that is required to support authority control and for the international sharing of authority data. The model focuses on data, regardless of how they

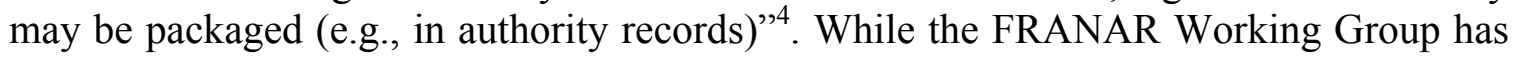

\footnotetext{
1 Functional Requirements for Bibliographic Records: Final Report. (1998). IFLA Study Group on the Functional Requirements for Bibliographic Records. München: KG Saur

2 "Family" entity was added in Functional Requirements for Authority Data - A Conceptual Model. (2009).

3 Functional Requirements for Authority Data - A Conceptual Model. (2009). IFLA Working Group on Functional Requirements and Numbering of Authority Records (FRANAR), ed. by Glenn E. Patton.

München: K.G. Saur. p.15.

${ }^{4}$ Ibid., p. 13.
} 
included some aspects of subject data in their model, they have not undertaken the full analysis of the entities and relationships relevant to subject authorities ${ }^{5}$.

As a result, the IFLA Working Group on the Functional Requirements for Subject Authority Records (FRSAR) was formed in 2005 to address subject authority data issues and to investigate the direct and indirect uses of subject authority data by a wide range of users. The FRSAR Working Group (2005 to present) and the FRANAR Working Group (1999 to 2009) both worked in parallel to develop models within the FRBR framework. By the time FRANAR released its final report in June 2009, FRSAR also had released its first draft report of the Functional Requirements for Subject Authority Data (FRSAD) for world-wide review. Since the two reports were developed independently, the relationship between the FRSAD and FRAD models is explained in Appendix B of this report.

${ }^{5}$ Functional Requirements for Authority Data - A Conceptual Model. (2009). IFLA Working Group on Functional Requirements and Numbering of Authority Records (FRANAR), ed. by Glenn E. Patton. München: K.G. Saur. p. 8. 


\section{PURPOSE AND SCOPE}

\subsection{Purpose}

Subject access to information has been a significant approach of users to satisfy their information needs. Research results have demonstrated that the integration of controlled vocabulary information with an information retrieval system helps users perform more effective subject searches. This integration becomes possible when subject authority data (information about subjects from authority files) are linked to bibliographic files and are made available to users.

The purpose of authority control is to ensure consistency in representing a value - a name of a person, a place name, or a term or code representing a subject — in the elements used as access points in information retrieval. For example, "World War, 1939-1945" has been established as an authorised subject heading in the Library of Congress Subject Headings (LCSH). When using LCSH, in cataloguing or indexing, all publications about World War II are assigned the established heading regardless of whether a publication refers to the war as the "European War, 1939-1945", "Second World War", "World War 2", "World War II", "WWII", "World War Two", or "2nd World War". The synonymous expressions lead to the authorised heading. This ensures that all publications about World War II can be retrieved by and displayed under the same subject heading, either in local catalogue or database or in a union catalogue.

In almost all large bibliographic databases, authority control is achieved manually or semi-automatically by means of an authority file. The file contains data about access points - names, titles, or subject terms - that have been authorised for use in bibliographic records. In addition to ensuring consistency in subject representation, a subject authority system may also record established semantic relationships among subject concepts and/or their labels. Data in a subject authority system are connected through semantic relationships, which may be expressed in subject authority records or generated according to specific needs (e.g., presenting the broader and narrower concepts) in printed or online displays of thesauri, subject headings lists, classification schemes, and other subject authority systems. Such systems have been referred to as "controlled vocabularies", "structured vocabularies", "concept schemes", "encoding schemes", and "knowledge organization systems" interchangeably depending on their function and structure, as well as according to the communities that use them. Given the purpose of this report, the discussions about subject authority data apply to all systems and structures referred to by these terms. The study follows FRBR's approach in that it makes no priori assumption about the physical structure or storage of authority data. 


\subsection{Scope}

The primary purpose of this study is to produce a framework that will provide a clearly stated and commonly shared understanding of what the subject authority data/record/file aims to provide information about, and the expectation of what such data should achieve in terms of answering user needs. The role of the FRSAR Working Group was defined in the following terms of reference:

- To build a conceptual model of Group 3 entities within the FRBR framework as they relate to the aboutness of works;

- To provide a clearly defined, structured frame of reference for relating the data that are recorded in subject authority records to the needs of the users of that data;

- To assist in an assessment of the potential for international sharing and use of subject authority data both within the library sector and beyond.

To fulfil these terms of reference, the FRSAR Working Group established two subgroups: User Tasks Sub-Group and Subject Entities Sub-Group.

The User Tasks Sub-Group focused on user studies and the definition of user tasks. For the purposes of this study, the users of subject authority data include information professionals who create and maintain subject authority data, information professionals who create and maintain metadata, intermediaries and end users who search for information to fulfil information needs. The functional requirements for subject authority data are defined in relation to the following general tasks that are performed by these users:

Find one or more subjects and/or their appellations, that correspond(s) to the user's stated criteria, using attributes and relationships;

Identify a subject and/or its appellation based on its attributes or relationships (i.e., to distinguish between two or more subjects or appellations with similar characteristics and to confirm that the appropriate subject or appellation has been found);

Select a subject and/or its appellation appropriate to the user's needs (i.e., to choose or reject based on the user's requirements and needs);

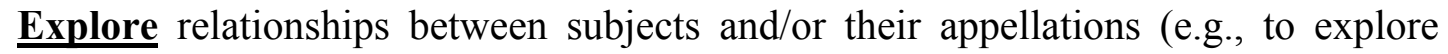
relationships in order to understand the structure of a subject domain and its terminology).

The Subject Entities Sub-Group focused on the Group 3 entities including the study of current FRBR Group 3 entities and alternatives in order to define: 
a) entities that can serve as subjects of a work (the "has as subject" relationship);

b) possible sub-entities in the Group 3 cluster; and

c) additional entities related to the Group 3 cluster.

The FRSAR Working Group is aware that some controlled vocabularies provide terminology to express other aspects of works in addition to subject (such as form, genre, and target audience of resources). While very important and the focus of many user queries, these aspects describe isness or what class the work belongs to based on form or genre (e.g., novel, play, poem, essay, biography, symphony, concerto, sonata, map, drawing, painting, photograph, etc.) rather than what the work is about. Some of these aspects are explicitly covered by the FRBR model, for example, "form of work," "intended audience," etc. as attributes of work. While the Group acknowledges that there are cases where a vocabulary provides terminology, or has been used, also for isness, the focus of the FRSAD model is on aboutness (the FRBR-defined relationship work "has as subject ..."). On the other hand, any case of a work about a form or genre (e.g. about romance novels, about dictionaries) clearly falls within the aboutness category.

\subsection{Aboutness and Ofness}

When modelling the fundamental classes of bibliographic entities we necessarily face the challenge of carrying out the most appropriate analysis of aboutness-i.e., the relation between a work and its subject matter. Aboutness is a concept that is central to the field of knowledge organization, and many authors have made significant contributions to our understanding of the nature of work-subject relations. Some of these contributions appear in the literature of library and information science (LIS), ${ }^{6,7,8}$ while others have been made by philosophers of logic and language ${ }^{9,10,11}$. A review of these literatures will show that there is not as much consensus on the nature of aboutness as one might hope to find: in fact, there are a wide variety of views.

At the risk of oversimplifying what is undoubtedly a complex situation, we might consider that it is possible to place views on aboutness on a spectrum whose poles represent the two extremes of "nominalism" (or, following Hjørland, "idealism") and "realism." For the thoroughgoing nominalist, it does not make sense to talk of works "having" or "being about" subjects - aboutness should be conceived not as a property of

\footnotetext{
${ }^{6}$ Wilson, P. (1968). Two kinds of power: An essay on bibliographic control. Berkeley, CA: University of California Press.

${ }^{7}$ Hutchins, W. J. (1977). On the problem of "aboutness" in document analysis. Journal of Informatics, 1 (1): 17-35.

${ }^{8}$ Hjørland, B. (1992). The concept of "subject" in information science. Journal of Documentation, 48 (2): 172-200.

${ }^{9}$ Ryle, G. (1933). “About.” Analysis, 1 (1): 10-12.

${ }^{10}$ Putnam, H. (1958). Formalization of the concept “about." Philosophy of Science, 25 (2): 125-130.

${ }^{11}$ Goodman, N. (1961). About. Mind, 70 (277): 1-24.

${ }^{12}$ Hjørland, op. cit.
} 
works but rather as a relation, constructed by a particular person at a particular time, between a particular set of works and a particular linguistic expression (i.e., a name or label). The realist, on the other hand, is content to proceed on the assumption that subjects are real things that exist separately from the linguistic expressions that we use to name them, and that it is possible to determine "the" subject(s) of any given work. Of course, there are other points of view on aboutness that may be located either at intermediate points between these two poles, or on different spectrums. But it is probably fair to say that most people who are actively engaged in the tasks of designing bibliographic classification schemes, indexing documents in accordance with such schemes, and using those schemes as tools for finding the kinds of documents we want, act in accordance with assumptions that are consistent with some version of the realist viewpoint.

Ultimately, the FRSAR Working Group does not take a philosophical position on the nature of aboutness, rather, it looks at the problem from the user's point of view. When confronted with an information need that can potentially be met by finding and using a document about a certain subject, the user both expects to be able to formulate a search statement specifying the subject, and expects that the tools and services at hand are capable of comparing such search statements with the subject statements generated by cataloguers and indexers.

Those LIS authors who have focused on the subjects of visual resources, such as artworks and photographs, have often been concerned with how to distinguish between the "aboutness" and the "ofness" (both specific and generic depiction or representation) of such works. ${ }^{13}$ In this sense, "aboutness" has a narrower meaning than that used above. A painting of a sunset over San Francisco, for instance, might be analyzed as being (generically) "of" sunsets and (specifically) "of" San Francisco, but also "about" the passage of time. Standard metadata schemas for cultural objects correspondingly allow for distinctions to be made among (a) description of the kinds of things depicted in works, (b) identification of the particular people, objects, events, and places depicted, and (c) interpretation of the meanings of works $^{14}$. The FRSAR Working Group recognizes that any statement on the "ofness" of a work can be a subject statement and is likely to be the target of a catalogue user's search. The FRSAD model is therefore applicable to situations where ofness statements (depiction) are included in subject access.

\footnotetext{
${ }^{13}$ Shatford, S. (1986). Analyzing the subject of a picture: A theoretical approach. Cataloging \& Classification Quarterly, 6 (3): 39-62.

${ }^{14}$ Categories for the Description of Works of Art (CDWA). (2000). Eds. Baca, M. and Harpring, P. The J. Paul Getty Trust and College Art Association. Los Angeles, CA: Getty Research Institute. Available at: http://www.getty.edu/research/conducting_research/standards/cdwa/index.html (accessed 2010-01-20).
} 


\subsection{Method}

The method used to build this conceptual model is the entity analysis technique used in FRBR. The development of such a conceptual model consists of the following steps ${ }^{15}$ :

1) The analysis starts with the user tasks as well as the key objects that are of interest to users in a specific domain.

2) The attention is not on individual data but on the "things" the data describe. Each of the objects of interest or entities defined for the model serves as the focal point for a cluster of data.

3) At a higher level, an entity diagram depicts the relationships that normally hold between one type of entity and another type of entity.

4) Important characteristics or attributes of each entity are then identified.

5) Each attribute and relationship is mapped to the user tasks. Relative values of importance are assigned to each attribute and relationship with specific reference to the task performed and the entity that is the object of the user's interest.

These steps were followed in the development of this model. The background of the initial conceptual analysis of user tasks and entities performed by the Group is explained in detail in Appendix A.

\subsection{Components of the Study}

The remainder of the report is divided into two major segments: the main body of the report follows the FRBR report structure and presents the entity-relationship model; the second segment contains four appendices that explain the methodology and implementation considerations.

The remaining body of the report consists of four chapters:

- Chapter 3 of the study identifies and defines the entities used in the model.

- Chapter 4 analyses the attributes associated with each of the entities defined in the model.

- Chapter 5 analyses the relationships used in the model, including the relationships operating both at the general level and between specific instances of entities.

- Chapter 6 presents the user tasks and then maps the attributes associated with each entity to the four generic user tasks the subject authority data is intended to support, showing the relevance of each attribute or relationship to each of the user tasks.

The appendices contain additional materials:

\footnotetext{
${ }^{15}$ Functional Requirements for Bibliographic Records: Final Report. (1998). IFLA Study Group on the Functional Requirements for Bibliographic Records. München: KG Saur. p.9. Section 2.3 Methodology.
} 
- Appendix A discusses the initial analysis used as basis in building the conceptual model for aboutness. It analyses the subject relationship and Group 3 entities introduced in FRBR as well as possible approaches to the model of aboutness.

- Appendix B explains the relationship of the FRSAD model with the FRBR and the FRAD models, given the fact that both FRAD and FRSAD are based on FRBR but were developed in parallel.

- Appendix $\mathrm{C}$ furthers the discussion of the importance of the FRSAD model and maps it with related developments including the ISO standard for thesauri, the W3C's Simple Knowledge Organization System (SKOS) and OWL Web Ontology Language, and the Dublin Core Abstract Model.

- Appendix D contains examples from existing subject authority systems through the perspective of the FRSAD model. 


\section{ENTITIES}

\subsection{Diagramming Conventions}

FRSAD follows the conventions used in both FRBR and FRAD:
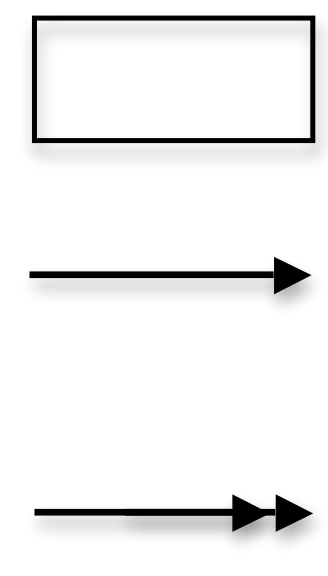

has appellation

is appellation of
A rectangle represents an entity.

A single-headed arrow on a line represents a relationship in which any given instance of the entity at the beginning of the line may be associated with only one instance of the entity to which the arrow is pointing.

A double-headed arrow on a line represents a relationship in which any given instance of the entity at the beginning of the line may be associated with one or more instances of the entity to which the arrow is pointing.

A relationship above the line indicates left-to-right direction; a relationship below the line indicates a right-toleft direction.

\subsection{General Framework}

The FRSAR Working Group proposes a generalisation of FRBR, as seen in Figure 3.1. This diagram is based on the original FRBR Figure 3.3 that depicts the "subject" relationships between works and entities in Group 1, Group 2, and Group 3. A new entity, family, added by FRAD in Group 2, is also reflected in this general framework. The entities in the third group represent an additional set of entities that serve as the subjects of works. The group includes, according to the FRBR model, concept (an abstract notion or idea), object (a material thing), event (an action or occurrence), and place (a location). 


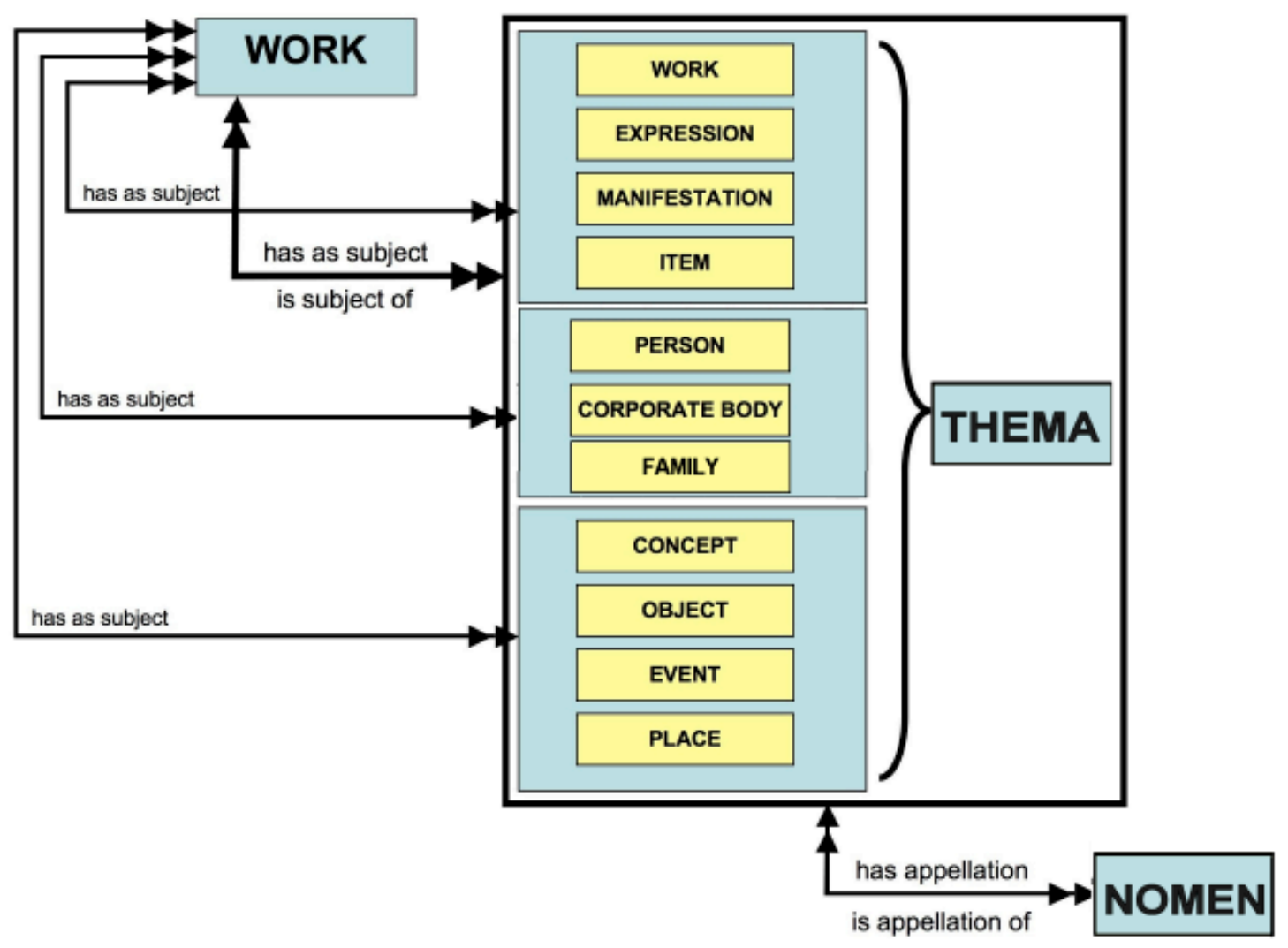

Figure 3.1 FRSAD's relation to FRBR (with the addition of FRAD entity family)

The FRSAR Working Group introduced the following two entities:

Thema: any entity used as a subject of a work

Nomen: any sign or sequence of signs (alphanumeric characters, symbols, sound, etc.) that a thema is known by, referred to, or addressed as.

The Functional Requirements for Subject Authority Data (FRSAD) model is presented as:

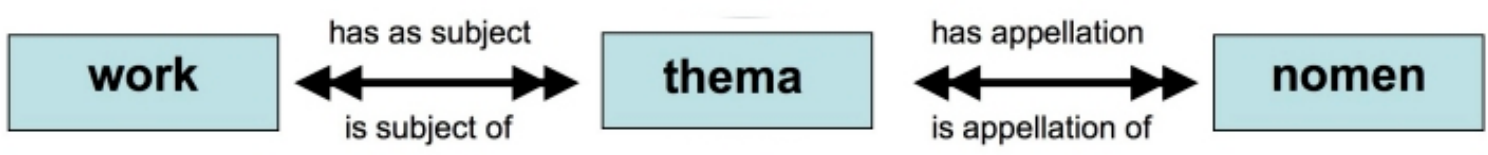

Figure 3.2 FRSAD conceptual model

Both "has as subject/is subject of" and "has appellation/is appellation of" relationships are many-to-many relationships. Any work can have more than one thema and any thema can be the subject of more than one work. We can take "A brief history of time: from the big bang to black holes" by Stephen W. Hawking as an example. The work has several themas: "cosmology", "space and time", "unification of physics", "black holes", "big bang", "history of time", "universe", etc. There are many other works about any of these 
themas. For any of the themas in this list (presented here as terms in English) there are other possible nomens in other languages and in different controlled vocabularies.

Some works are perceived as having no thema as subject (such as certain musical works or abstract artwork), and no subject access is provided to them. These cases are not covered by FRSAD. The cases of a thema without a nomen are also beyond the scope of this model.

\subsection{Choice of Terms for FRSAD Entities}

The Working Group chose Latin terms, thema (plural themata or themas) and nomen (plural nomina or nomens), because they have no pre-existing meaning in our context, are culturally neutral and do not require translation. For thema, other possible (English) terms include "subject", "topic", and "concept"; however, even discussions within the Working Group proved that there are very different views on granularity (some see "subject" and "topic" as synonyms, while others see "topic" as a component of "subject"). The Working Group needed to distinguish thema from the previously defined FRBR entity concept because thema is a superclass of all FRBR entities (to be explained in the next section). For nomen, it is the case that the term "name" is often considered synonymous with proper name. In addition, the Working Group needed to distinguish nomen from the FRAD entity name because nomen includes FRAD entities name, identifier, and controlled access point.

\section{$3.4 \quad T H E M A$}

Thema is defined as "any entity used as a subject of a work". Therefore this model confirms one of the basic relationships defined in FRBR: WORK has as subject THEMA / THEMA is subject of WORK.

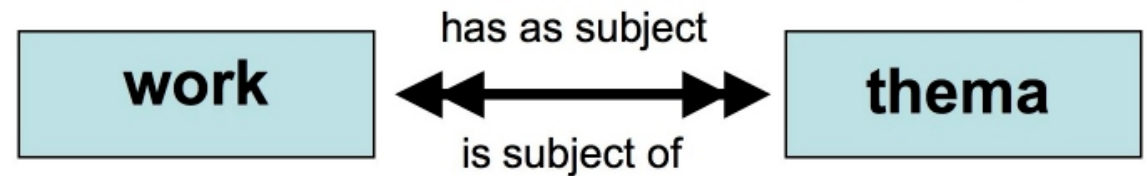

Figure 3.3 Work-Thema relationship

According to Delsey, the first broad objective of FRSAD is to ensure that the scope of the entities defined is sufficient to cover everything that a user of a library catalogue might view as a "subject" the point of view of end-users and intermediaries, thema comprises the aboutness of the

\footnotetext{
${ }^{16}$ Delsey, T. (2005). Modeling subject access: Extending the FRBR and FRANAR conceptual models. Cataloging \& Classification Quarterly 39 (3/4): 49-61.
} 
(possibly unknown) resources that will satisfy the information need. From the point of view of information professionals who create metadata, one or more themas capture the aboutness of a particular resource.

Within the FRBR framework, thema, which can be viewed as an entity on its own and also as a super-entity or superclass, includes existing Group 1 and Group 2 entities, and additionally, all others that serve as the subjects of works (i.e., Group 3). In other words, thema is a superclass of all FRBR entities (Figure 3.4). Defining thema as a super entity enables modelling of relationships and attributes on a more general and abstract level.

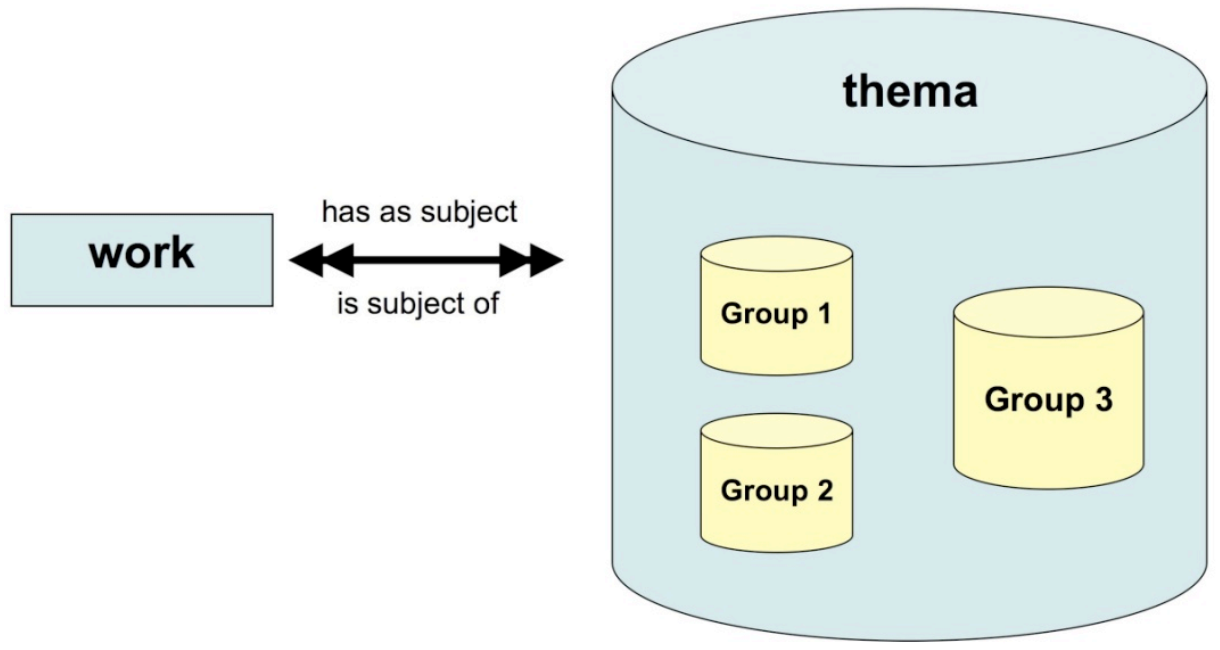

Figure 3.4 Within the FRBR framework, thema includes existing Group 1 and Group 2 entities and, in addition, all others that serve as the subjects of works (i.e., Group 3)

While the original FRBR Group 3 entities (object, concept, event, place) may be used in a given implementation, the Working Group does not propose them as a universally applicable set of Group 3 entities. In a particular application themas would normally have implementation-specific types; but, based on the pilot study, as explained in Appendix A, there seems to be no generally applicable categorization of thema. Appendix D provides examples of existing implementations through the perspective of the FRSAD model.

Themas can vary substantially in complexity or simplicity. Depending on the circumstances (the subject authority system, user needs, the nature of the work, etc.) the aboutness of a work can be expressed as a one-to-one relationship between the work and the thema; this means that the totality of the aboutness is encompassed in a single thema. In other circumstances the relationship is one-to-many, meaning that the aboutness of the work is captured in two or more themas. It is virtually impossible to define what the universal "atomic" level of a thema might be, because any thema can be fragmented further. The argument can be reversed: simple themas may be combined or aggregated, resulting in more complex thema(s). In each particular implementation the atomic level is specified and rules guide the creation of nomens for complex themas. 
To some extent the granularity of a thema also depends upon the controlled vocabulary used for its appellation(s). Often the complexity of a thema is associated with the complexity of the nomen by which it is represented. Since the proposed model introduces a clear split between the thema ("the thing") and the nomen ("the label" used to refer to it), the complexity of the semantic and syntactic rules for creating or establishing a nomen is not directly reflected in the complexity of the thema, nor is it completely independent. Some types of controlled vocabularies (such as subject headings systems) enable the establishment of complex themas (e.g., by creating pre-coordinated strings), while others (such as thesauri) are mainly conceived for the use of more atomic themas.

\subsection{NOMEN}

The FRSAD model proposes a new relationship: THEMA has appellation NOMEN/NOMEN is appellation of THEMA (Figure 3.5).

Nomen is defined as "any sign or sequence of signs (alphanumeric characters, symbols, sound, etc.) that a thema is known by, referred to, or addressed as. Examples include "love," " $\infty$," or "595.733." A Nomen can be human-readable or machine-readable. Nomen is a superclass of the FRAD entities name, identifier, and controlled access point.

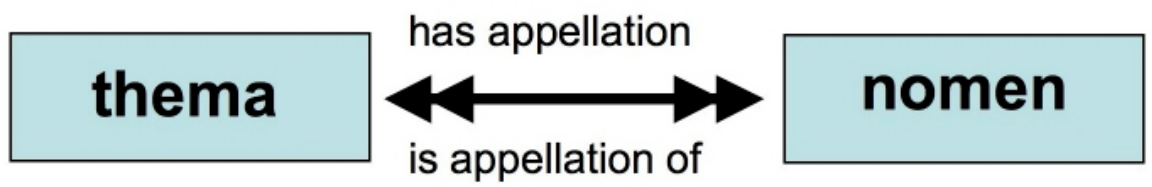

Figure 3.5 Thema-Nomen relationship

In general (i.e., in natural language or when mapping different vocabularies) the "hasappellation/is appellation of" relationship is a many-to-many relationship. A thema has one or more nomens and there may be a nomen referring to more than one thema. In a given controlled vocabulary, however, a nomen should be an appellation of only one thema, as illustrated in Figure 3.6. See Appendix D for examples from subject authority systems.

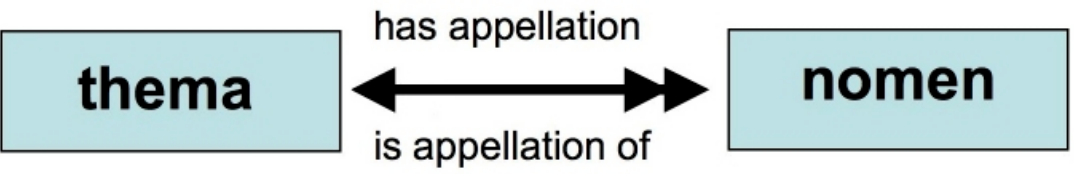

Figure 3.6 Thema-Nomen relationship within a controlled vocabulary 


\section{ATTRIBUTES}

\subsection{Attributes of a THEMA}

In the FRSAD model, the entity thema is defined in a very abstract and general way. Attributes of a thema are implementation-dependent and will vary. "Type" and "scope note" can be considered general attributes, but particular values of "type" are, again, implementation-dependent. In any implementation there will normally be additional attributes of a thema other than "type" and "scope note". Those attributes will be dependent on both the type of themas and the application domain.

\subsubsection{Type of thema}

The category to which a thema belongs in the context of a particular knowledge organisation system.

In an implementation themas can be organised based on category, kind, or type. This report does not suggest specific types, because they may differ depending on the implementation (see Appendix A).

For example, in some implementations the original FRBR entities work, expression, manifestation, item, person, family, corporate body, concept, object, event, and place can be used as types, perhaps even adding time as has been suggested (see Appendix A.2). In general, any entity defined in FRBR and/or FRAD may become a type of thema. And their attributes (also defined in FRBR and FRAD) will equally apply.

In other implementations, a different set of types may be defined. Two examples from existing implementations, UMLS and AAT, are presented below. Detailed explanations of these subject authority systems can be found in Appendix D.

1) Unified Medical Language System (UMLS) semantic types ${ }^{17}$

Entities

Physical Object

Organism

Anatomical Structure

\footnotetext{
${ }^{17}$ National Library of Medicine. (2003-). Unified Medical Language System. Current Semantic Types. UMLS 2004AB Documentation. Last updated: 21 March 2008. Available at:

http://www.nlm.nih.gov/research/umls/META3_current_semantic_types.html (accessed 2010-01-20).
} 


\author{
Manufactured Object \\ Substance \\ Conceptual Entity \\ Idea or Concept \\ Finding \\ Organism Attribute \\ Intellectual Product \\ Language \\ Occupation or Discipline \\ Organization \\ Group Attribute \\ Group
}

\title{
Events
}

Activity

Phenomenon or Process

2) Art and Architecture Thesaurus (AAT) facets ${ }^{18}$

[Top of the AAT hierarchies]
Associated Concepts
Physical Attributes
Styles and Periods
Agents
Activities
Materials
Objects

These examples show very different approaches to defining types of themas. In the UMLS, themas are first differentiated as "Entity" or "Event." The types of UMLS "Entity" are "Physical Object" or "Conceptual Entity." The types of "Events" are grouped into "Activity" and "Phenomenon or Process." In AAT, all themas are categorized into seven types: "Associated Concepts," "Physical Attributes," "Styles and Periods," "Agents," "Activities," "Materials," and "Objects."

Clearly since themas are very different, they will also necessarily have different attributes. In the first example "Substance" (a physical object) will have very different attributes from "Organization" (a conceptual entity) in the UMLS. The same is true for the attributes of "Styles and Periods," "Agents," and "Materials" in the AAT.

\footnotetext{
${ }^{18}$ Art and Architecture Thesaurus Online Hierarchy Display. In: Art and Architecture Thesaurus. (2000-). Los Angeles: J. Paul Getty Trust, Vocabulary Program. Available at:

http://www.getty.edu/vow/AATHierarchy?find $=\&$ logic $=$ AND\&note $=\&$ english $=$ N\&subjectid $=300000000$ (accessed 2010-01-20).
} 
Another possible distinction can be made at the thema level between Classes and Instances. These two types of thema are fundamental and many subject authority systems recognize them. The Class/Instance distinction is essentially equivalent to the universal/particular distinction, typically made on the basis of instantiability (and hence is sometimes characterized in philosophical literature as a kind/instance distinction).

For example:

$\begin{array}{ll}\text { Class } & \text { Instance } \\ \text { Palaces } & \text { Buckingham Palace } \\ \text { Ships } & \text { The Lusitania } \\ \text { Battles } & \text { The Battle of Hastings }\end{array}$

\subsubsection{Scope Note}

A text describing and/or defining the thema or specifying its scope within the particular subject authority system.

\subsection{Attributes of a NOMEN}

The attributes of a nomen listed below represent the most common (general) attributes. Not all are applicable in every case, and the list is not comprehensive. While all listed attributes are applicable to individual instances of nomens, some may also be used for an entire subject authority system and declared on that level. The examples of attribute values are illustrative only and should not be seen as prescriptive. In any particular implementation the actual values of an attribute are selected from a controlled list and/or are coded.

In addition to the proposed general attributes, presented here, there may be additional, implementation-specific attributes.

Current subject authority records typically include other elements such as administrative data. Also, current authority system may allow merging data -- which describe both thema(s) and nomen(s) -- into one record. As this is a conceptual model, such aspects of implementation are not discussed.

\subsubsection{Type of nomen}

Category to which the nomen belongs.

In addition to other implementation-specific types, there are two important values of this attribute: 


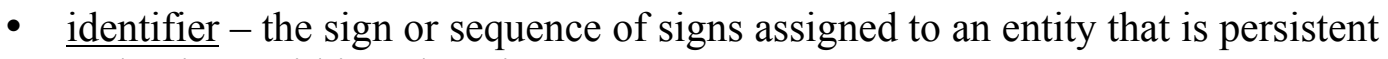
and unique within a domain

- controlled name - the name constructed during the authority control or vocabulary maintenance process that usually serves as an access point (note: labelled as controlled access point in FRAD).

If needed, the values of the type attribute may be further refined; for example, additional refinement may include different kinds/formats of identifiers (e.g., URI, ISBN).

\subsubsection{Scheme}

The scheme in which the nomen is established, including value encoding schemes (subject heading lists, thesauri, classification systems, name authority lists, etc.) and syntax encoding schemes (standards for encoding dates, etc.).

Examples of attribute values:

- LCSH

- DDC

- UDC

- ULAN

○ ISO 8601

\subsubsection{Reference Source of nomen}

The source in which the nomen is found. It may also be modelled as a relationship with the appropriate Group 1 entity.

Examples of attribute values:

- Encyclopaedia Britannica

○ Webster's Third New International Dictionary (1961)

- Columbia Gazetteer

\subsubsection{Representation of nomen}

The data type in which the nomen is expressed.
Examples of values:
$\circ$ alphanumeric
o sound
o graphic

\subsubsection{Language of nomen}

The language in which the nomen is expressed.

Examples of values: 
○ English

- Greek

- Chinese

- Slovenian

\subsubsection{Script of nomen}

The script in which the nomen is expressed.

Examples of values:

○ Cyrillic

o Thai

- Chinese (Simplified)

- Chinese (Traditional)

\subsubsection{Script conversion}

The rule, system, or standard used to render the nomen in a different representation.

Examples of values:

- Pinyin

- ISO 3602, 1998, Romanisation of Japanese (kana script)

\subsubsection{Form of nomen}

Any additional information that helps to interpret the nomen.

Examples of attribute values:

- Full name

- Abbreviation

○ Formula

\subsubsection{Time of validity of nomen}

The time period, in which the nomen is/was used or is/was valid within a subject vocabulary system.

This should not be confused with the temporal aspect of a thema.

Examples of values:

○ until May 11, 1949

○ after 1945

○ $1945-1967$

\subsubsection{Audience}

The community or user group for which the nomen is the preferred form. 
In the global environment it is usually impossible to declare one nomen of a thema to be the preferred form. The notion of "preferred" form can, in general, be tied only to a particular community, defined by name, rule, or convention.

Examples of values:

$\circ$ English-speaking users

○ Scientists

○ Children

\subsubsection{Status of nomen}

The status of the nomen in a subject authority system.

This should not be confused with the management of a subject authority system (e.g., including or excluding a thema).

Examples:

- Proposed

- Accepted

- Obsolete 


\section{RELATIONSHIPS}

The FRSAD model establishes two sets of relationships:

1) Relationships between different types of entities: WORK-to-THEMA and THEMA-to-NOMEN. These are the primary relationships and are also illustrated in Chapter 3 where the entities are presented.

2) Relationships between entities of the same type: THEMA-to-THEMA and $N O M E N$-to-NOMEN. These are presented in detail in this chapter.

\subsection{WORK-to-THEMA Relationship}

The Work-to-Thema relationship is discussed in Section 3.2. In the FRSAD model, thema includes existing Group 1 and Group 2 entities and all entities that serve as the subjects of works. Their relationships can be illustrated as:

Work has as subject Thema / Thema is subject of Work

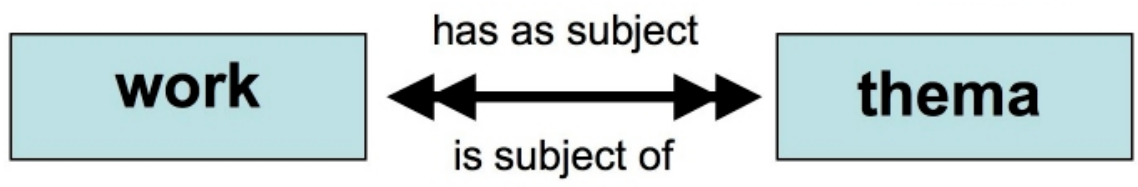

(From Figure 3.3 Work-Thema relationship)

Thema refers to anything that can be the subject of a work. Presented within the entityrelationship model, the WORK-to-THEMA relationship is many-to-many: any work can have one or more themas, and any thema may be the subject of one or more works.

\section{$5.2 \quad T H E M A$-to-NOMEN Relationship}

The THEMA-to-NOMEN relationship is specified with the following statements:

Thema has appellation Nomen / Nomen is appellation of Thema

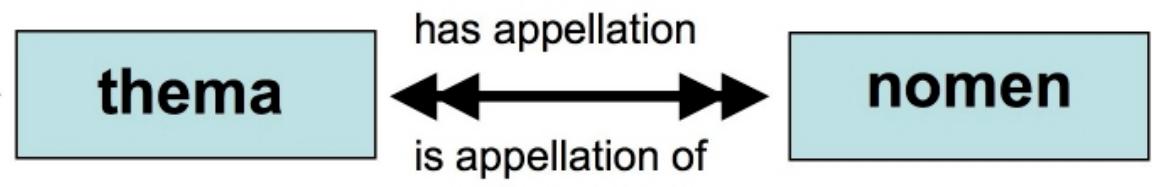

(From Figure 3.5 Thema-Nomen relationship) 


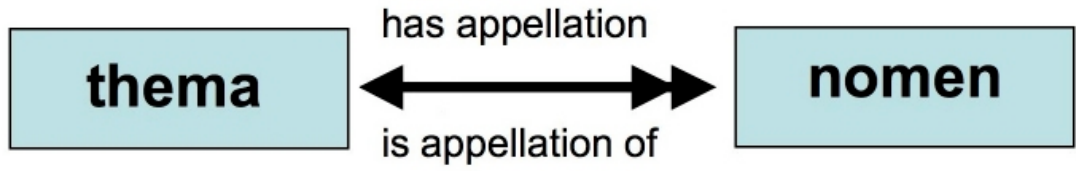

(From Figure 3.6 Thema-Nomen relationship within a controlled vocabulary)

As stated in Section 3.4, in general (i.e., in natural language or when mapping different vocabularies) the relationship "has appellation/is appellation of" is a many-to-many relationship. Any thema may have more than one nomen (see Figure 3.5); and any nomen may be the appellation of more than one thema. In subject authority-related processes such as integrating or mapping controlled vocabularies, this condition may result in ambiguity regarding the meaning, scope, and definition of themas represented by the same nomen. Therefore, in a given controlled vocabulary, a nomen normally is an appellation of only one thema but a thema can have more than one nomen (see Figure 3.6). Based on this general principle, a more complex nomen, for example, with added qualifiers, must be constructed when necessary in order to eliminate ambiguity.

\subsection{THEMA-to-THEMA Relationships}

Only relationships directly applicable for subject access are analyzed here. The FRBR and FRAD models cover additional entity-to-entity relationships such as relationships between works.

In order to ensure that (1) the attributes relevant to the construction and use of subject authority data are adequately covered, and (2) the model provides a clear and pragmatic representation of the relationships that are "reflected through subject access points in bibliographic records as well as those reflected in the syndetic structure of thesauri, subject headings lists, and classification schemes and in the syntactic structure of indexing strings" 19 , the thema-to-thema relationship types are discussed in the context of subject authority systems.

\subsubsection{Hierarchical Relationships}

Hierarchical structures show relationships between and among concepts and classes of concepts. Hierarchical relationships reveal degrees or levels of superordination and subordination, where the superordinate term represents a class or a whole, and subordinate terms refer to its members or parts. Hierarchical structures are found in classification schemes, subject heading systems, thesauri, and other knowledge organization systems. Used in the bibliographic universe, hierarchical relationships provide disambiguation functions to assist with the identify user task. Yet they are the

\footnotetext{
${ }^{19}$ Delsey, T. (2005). Modeling subject access: Extending the FRBR and FRANAR conceptual models.
} Cataloging \& Classification Quarterly 39 (3/4): 49-61. 
most effective in furthering linking and navigation objectives, and satisfying the select, and especially, the explore user tasks. They are of particular aid to users with undefined or very broad information needs and they also allow users to improve their searching.

Typically, a hierarchical relationship may be one of three types: the generic relationship, the hierarchical whole-part relationship, and the instance relationship ${ }^{20}$. Some concepts can belong to more than one superordinate concept simultaneously. They are considered to have polyhierarchical relationships. Other perspective hierarchical relationships also exist (as explained in Section 5.3.1.5).

\subsubsection{The Generic Relationship}

The generic relationship is the logical relationship of inclusion. The primary function of the hierarchical relationship is to convey the same concept, but at different levels of specificity ${ }^{21}$. "Of limited domain and range, it is strictly defined in terms of the properties of reflexivity, anti-symmetry, and transitivity" 22 . It is sometimes represented as the "allsome" relationship. For example, all parrots are birds, and some birds are parrots. But not all parrots are pets therefore the genus-species relationship between parrots and pets does not exist in logic ${ }^{23}$. In the computer science literature and formal ontology construction, the characteristic of "inheritance" of genus-species relationships is also widely presumed. This "hierarchical force" assumes that what is true of a given class (e.g., furniture) is true of all member-classes it subsumes (chairs, tables, and so on.)

\subsubsection{The Whole-Part Relationship}

The whole-part relationship covers situations where one concept is inherently included in another, regardless of context, so that concepts can be organized into hierarchies (with the "whole" treated as a broader term). For example, blood vessels are part of the cardiovascular system in anatomy.

In addition to physical component part relationships, "whole and part" can be applied to several common types of situations such as geographical regions, hierarchical organizational structures, disciplines or fields of discourse. Because such relationships, being synthetic rather than analytic, are not necessarily or logically true in subject authority systems they may be differentiated as special hierarchical relationships (rather than genus-species and perspective hierarchies) or as associative relationships.

\footnotetext{
${ }^{20}$ ISO (2009). ISO/CD 25964-1, Information and documentation - Thesauri and interoperability with other vocabularies - Part 1: Thesauri for information retrieval. ISO/TC 46 / SC 9 ISO 25964 Working Group.

${ }^{21}$ Clarke, S.G. (2001). Thesaural relationships. In: Relationships in Knowledge Organization. Eds. Bean, C.A. and Green, R. Dordrecht: Kluwer. p. 42.

${ }^{22}$ Svenonius, E. (2000). The Intellectual Foundation of Information Organization. Cambridge, Mass.: MIT Press, p.151.

${ }^{23}$ Svenonius, op. cit.
} 


\subsubsection{The Instance Relationship}

The instance relationship identifies the link between a general class of things or events, expressed by a common noun, and an individual instance of that category, expressed by a proper noun. For example, "Mydoom" and "ILOVEYOU" are two instances of "computer worms" that are expressed by proper nouns.

\subsubsection{Polyhierarchical Relationship}

Some concepts can belong to more than one superordinate concept and are therefore considered to possess polyhierarchical relationships. These relationships can be (a) generic, e.g., music instrument "organ" belongs under both the "wind instrument" hierarchy and the "keyboard instrument" hierarchy; (b) whole-part, e.g., "biochemistry", is part of "biology" and is also part of "chemistry"; or (c) more than one type, e.g., "skull", belongs under the "bones" (kind-of), and also under the "head" (part-of), hierarchies ${ }^{24}$.

\subsubsection{Other Hierarchical Relationship}

Other hierarchical relationships, which do not have the logical properties of the above hierarchies, are seen often in subject authority systems. This may be partially due to the requirements of literary warrant (the natural language used to describe content objects), user warrant (the language of users), and sometimes, organizational warrant (the needs and priorities of the organization $)^{25}$. Their value is that they provide points of view about a concept and the aspect under which it is considered. For instance, although an insect can belong to only one genus-species hierarchy (e.g., Arthropoda), it can belong to as many perspective hierarchies as there are aspects of insects to be studied. In a classification scheme, an insect can be looked at, or studied, from the point of view of agricultural pests, disease carriers, food, and control technology ${ }^{26}$. Other reasons to employ such hierarchies are that concepts and terms like "happiness" are poly-semantic, vague, or ambiguous. Hence there might be no agreement as to what genus (class) such concepts belong to.

\subsubsection{Associative Relationships}

Associative relationships cover affiliations between pairs of themas that are not related hierarchically yet are semantically or conceptually connected and co-occurring. Associative relationships between themas are made explicit in some of the subject authority systems.

\footnotetext{
${ }^{24}$ Examples are from ISO (2009). ISO/CD 25964-1, Information and documentation - Thesauri and interoperability with other vocabularies - Part 1: Thesauri for information retrieval. ISO/TC 46 / SC 9 ISO 25964 Working Group.

${ }^{25}$ NISO. (2005). ANSI/NISO Z39.19-2005. Guidelines for the Construction, Format, and Management of Monolingual Controlled Vocabularies. Bethesda, Maryland: NISO Press.

${ }^{26}$ Svenonius, op. cit.
} 
In general, associative relation links are established among themas belonging to different hierarchies, or among overlapping themas within the same array on a particular level of the hierarchy. Most commonly considered associative relationships fall into these categories $^{27,28,29}$ :

Associative Relationships
Cause / Effect
Process / Agent
Action / Product of the action
Action / Patient or Target
Concept or Thing / Properties
Thing or Action / Counter-agent
Thing/ Its parts (if it does not
qualify for the hierarchical
whole-part relationship)
Raw material / Product
Action / Property
Field of study/ Objects or
phenomena studied

\section{Examples}

accident / injury

velocity measurement / speedometer

weaving/cloth

teaching / student

steel alloy / corrosion resistance

pest / pesticide

car / engine

grapes / wine

communication/communication skills

forestry/forests

In each particular implementations, a decision would be made about whether to include associative relationships and if so, which ones to include and at what level of specificity.

\subsubsection{Other Approaches to Semantic Relationships}

In the literature and in practice, other approaches to differentiate semantic relation types have been used. A taxonomy of subject relationships, compiled in 1996 and shared at an American Libraries Association (ALA) conference, listed over a hundred associative relationships and 26 hierarchical relationships ${ }^{30}$. Over 40 in the associative group and 20 in the hierarchical group have been verified by other sources ${ }^{31}$.

\footnotetext{
${ }^{27}$ Lancaster, F.W. (1986). Vocabulary Control for Information Retrieval. 2nd ed. Arlington, Virginia: Information Resources Press.

${ }^{28}$ NISO. op.cit.

${ }^{29}$ Aitchison, J., A. Gilchrist, and D. Bawden (2000). Thesaurus Construction and Use: A Practical Manual. 4th ed. London: Fitzroy Dearborn.

${ }^{30}$ Michel, D. (1996). Taxonomy of Subject Relationships. Appendix B (Part 2), Final Report to the ALCTS/CCS Subject Analysis Committee, submitted by Subcommittee on Subject

Relationships/Reference Structures. ALA Association for Library Collections and Technical Services (ALCTS) Cataloging and Classification Section (CCS) Subject Analysis Committee (SAC). Available at: http://www.ala.org/ala/mgrps/divs/alcts/mgrps/ccs/cmtes/subjectanalysis/subjectrelations/msrscu2.pdf Also available is the hierarchical display of this Taxonomy, at: http://www.ala.org/ala/mgrps/divs/alcts/mgrps/ccs/cmtes/sac/inact/subjectrelations/appendixbpartii.cfm (accessed 2010-03-31).

${ }^{31}$ Subcommittee on Subject Relationships/Reference Structures. (1997). Final Report to the ALCTS/CCS Subject Analysis Committee. ALA Association for Library Collections and Technical Services (ALCTS) Cataloging and Classification Section (CCS) Subject Analysis Committee (SAC). Available at: http://www.ala.org/ala/mgrps/divs/alcts/mgrps/ccs/cmtes/sac/inact/subjectrelations/finalreport.cfm
} 
The Unified Medical Language System (UMLS) ${ }^{32}$ classified semantic relationship types into two main groups and a number of sub-groups:

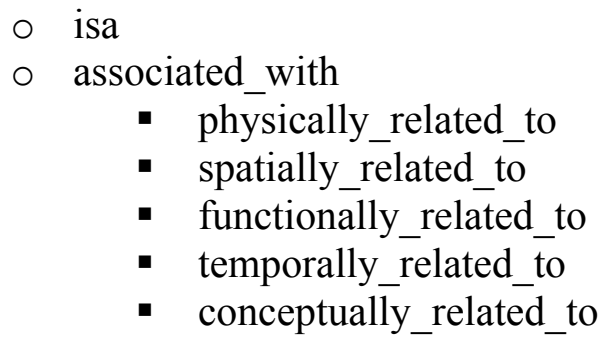

Spatial relationship types in UMLS include location_of, adjacent_to, surrounds, and traverses.

Whereas in another case, such relationship types for geographical regions only are identified as ${ }^{33}$ :

Inherently spatial

Containment

Overlap

Proximity

Directional

Explicitly stated

PartOf

AdministrativePartOf

AdministrativePartitionMemberOf

AdministrativeSeatOf

ConventionallyQualifiedBy

SubfeatureOf

GeophysicalPartitionMemberOf

PhysicallyConnectedTo

FlowsInto

These examples illustrate implementation-dependent relationship typing.

\footnotetext{
${ }^{32}$ National Library of Medicine. (2004) Unified Medical Language System. Current relations in the semantic network. In: NLM. Unified Medical Language System-Semantic Network Documentation, Section 3. Semantic Networks. Available at: http://www.nlm.nih.gov/research/umls/META3_current_relations.html (accessed 2010-01-20).

${ }^{33}$ Hill, L. (1999). Content standards for digital gazetteers. Presentation at the JCDL2002 NKOS Workshop "Digital gazetteers--Integration into distributed digital library services", July 18, 2002, Portland, Oregon. Available at: http://nkos.slis.kent.edu/DL02workshop.htm (accessed 2010-01-20).
} 


\section{$5.4 \quad N O M E N$-to-NOMEN Relationships}

Only the equivalence and whole-part relationships are discussed below. Other nomen-tonomen relationships may also be established.

\subsubsection{Equivalence Relationship}

Equivalence of nomen is a very important notion in subject access. Two nomens are equivalent if they are appellations of the same thema. The equivalence relationships in a monolingual controlled vocabulary can be found in five general situations: ${ }^{34,35}$

a) the nomens are synonyms

b) the nomens are near or quasi-synonyms

c) the nomens have lexical variants

d) a nomen is regarded as unnecessarily specific and it is represented by another nomen with broader scope

e) a nomen is regarded as unnecessarily specific and it is represented by a combination of two or more terms (known as "compound equivalence").

It is obvious that equivalence relationships do not assume exact equivalence. Inexact and partial equivalence are often found in controlled vocabularies. In reality, the nomens in the above d) and e) situations represent different themas. But since in some controlled vocabularies these nomens are connected as preferred and alternative terms, it may be interpreted that these nomens are assumed to represent the same thema in a controlled vocabulary.

In addition, equivalence relationships exist between nomens in different languages and across schemes. For example, "iron" (a term in English), "železo" (a term in Slovenian), and "Fe" (a chemical symbol) are all nomens for the same metal and are therefore considered equivalent.

The equivalence relationships of nomens can be specified further. For example:

- Replaces/Is replaced by

[e.g., "integrated plant control" is replaced by "centralized control"]

○ Has variant form/Is variant form

- Has acronym/is acronym for [e.g., "VS" is acronym for "virtual storage"]

- Has abbreviation/Is abbreviation of

- Has transliterated form/Is transliteration of

\subsubsection{The Whole-Part Relationship}

The whole-part relationship also exists between nomens. A nomen may have components (parts). These components may or may not be a nomen on their own. The composition of

\footnotetext{
${ }^{34}$ ISO. (2009). ISO/CD 25964-1. op. cit.

${ }^{35}$ NISO. (2005). Z39.19-2005. op.cit.
} 
such nomen may be governed by rules, for example, the citation order in faceted classification schemes or the order of subdivisions in a subject heading. 


\section{USER TASKS}

\subsection{Users and Use}

During the early stages of developing the entity-relationship conceptual model of subject authority records, the FRSAR Working Group considered it essential to analyze the users of subject authority data, to identify the contexts in which the data is used, and to characterize different usage scenarios.

Potential user groups include:

a) information professionals who create and maintain subject authority data, including cataloguers and controlled vocabulary creators;

b) information professionals who create and maintain metadata;

c) reference services librarians and other information professionals who search for information as intermediaries; and

d) end-users who search for information to fulfil their information needs.

Intermediaries (group c) act on behalf of end-users (group d). They interact with the bibliographic data in a similar way as end-users (although at a higher level of expertise). Therefore, for the purpose of this use analysis the intermediaries and end-users are considered belonging to the same end-user group.

Figure 6.1 illustrates the three-point perspective of subject authority data users.

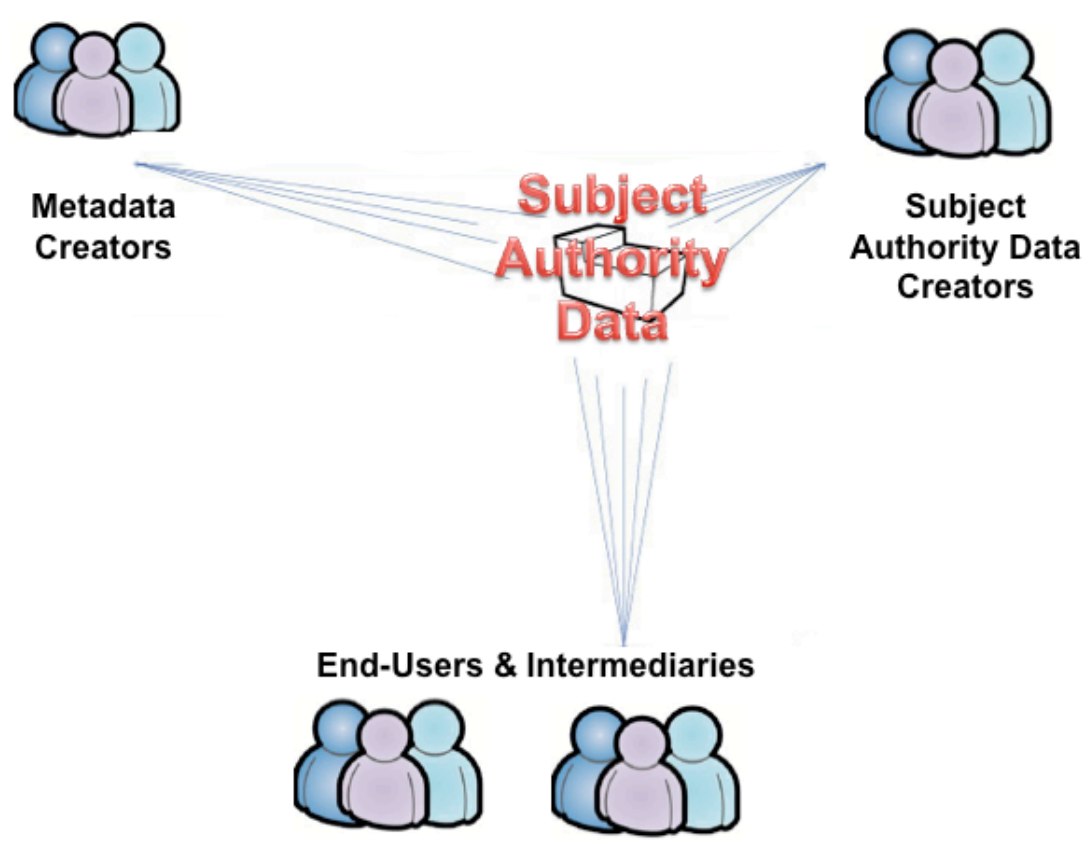

Figure 6.1 Users of subject authority data 


\subsection{User Tasks}

When using subject authority data, a user may need to find, identify, and select a subject entity or entities. A user may also choose to explore a subject domain and its terminology as well as the relationships that exist among the themas. In addition, the user may explore the correlation of the nomen(s) of a thema in one subject authority system to the respective nomen(s) of the same thema in another subject authority system.

Based on the results from the two user studies conducted by the User Tasks Sub-Group, four tasks for subject authority data have been defined:

- Find one or more subjects and/or their appellations, that correspond(s) to the user's stated criteria, using attributes and relationships;

- Identify a subject and/or its appellation based on their attributes or relationships (i.e., to distinguish between two or more subjects or appellations with similar characteristics and to confirm that the appropriate subject or appellation has been found);

- Select a subject and/or its appellation appropriate to the user's needs (i.e., to choose or reject based on the user's requirements and needs);

- Explore relationships between subjects and/or their appellations (e.g., to explore relationships in order to understand the structure of a subject domain and its terminology).

The explore user task is a new task introduced in FRSAD; whereas the find, identify, and select user tasks have been previously introduced in the FRBR and/or FRAD conceptual models. The subject authority data use survey conducted by FRSAR's User Tasks SubGroup indicates that a large number of participants $(69 \%)$ use subject authority data to explore relationships among terms during cataloguing and metadata creation. In addition, $62 \%$ of participants use subject authority data to explore relationships while searching for bibliographic resources, and 64\% use these data to navigate and browse bibliographic descriptions. These numbers reflect a major use of subject authority data for a task that was not present in the FRAD and FRBR models; therefore, the group deemed it important to add the explore user task.

Figure 6.2 shows a comparison of user tasks as defined in FRBR, FRAD, and FRSAD. 
User Tasks

\begin{tabular}{|l|l|l|}
\hline FRBR & FRAD & FRSAD \\
\hline Find & Find & Find \\
Identify & Identify & Identify \\
Select & & Select \\
Obtain & & Explore \\
& & \\
& Contextualize & \\
\hline
\end{tabular}

Figure 6.2 Comparison of user tasks as defined in FRBR, FRAD, and FRSAD

\subsection{Assessing Values Relative to User Tasks}

While in some cases the users' information needs are limited to authority data only, in most cases the users will utilise subject authority data to find, identify, select, and/or obtain Group 1 entities as specified by the FRBR user tasks.

The following is a list of tasks that result from placing the primary subject authority data user tasks (find, identify, select, and explore) in the context of different user groups as it relates to interacting only with subject authority data. The activities of using subject authority data to access bibliographic data are covered by FRBR. In the following examples, text within double quotation marks represents a nomen; a thema is referred by English text within curly brackets. Single quotations marks are used for thema types.

FIND: using the data to find one or more subjects and/or their appellations, that correspond(s) to the user's stated criteria, using attributes and relationships

1) Using subject authority data to find a thema or a set of themas based on the user's search criteria. For example:

- A user is looking for a thema of the type 'substance' within the medical field.

- A user is looking for a thema that is a 'medical condition(s)' for which \{chloromadinone acetate\} is used for treatment.

- A user is looking for themas that are particular artistic styles (for example, \{modernism\}) using thema-to-thema hierarchical relationships.

2) Using subject authority data to find a nomen or a set of nomens for a thema. For example:

- A user is looking for the Dewey Decimal Classification number (nomen) for the thema \{dragonflies\} (as it is referred to in English). 
- A user is looking for the preferred nomen in the Library of Congress Subject Headings for the thema \{lilac flower\} (as commonly referred to in English).

\section{IDENTIFY: using the data to identify a subject and/or its appellation based on their attributes or relationships}

3) Using subject authority data to identify a thema, i.e., to confirm that the thema found is the one sought by the user, or to distinguish between two similar themas. For example:

- A user is employing subject authority data to identify whether the thema \{clothing\} or the thema \{costume\} is more appropriate for a specific information need.

4) Using subject authority data to identify a nomen, i.e., to confirm that the nomen found is the one sought by the user, or to distinguish between two similar nomens. For example:

- A user employs subject authority data to verify whether the nomen "craftsman style" is the appropriate nomen in a particular system.

SELECT: using the data to select a subject and/or its appellation appropriate to the user's needs

5) Using subject authority data to select a thema from the set of themas found. For example:

- Select a thema at the appropriate level of specificity from a hierarchy of related themas: A user is using subject authority data to select the thema $\{$ volley ball $\}$ as a more appropriate subject access point in a bibliographic record rather than the broader thema \{ball games\}.

6) Using subject authority data to select a nomen from the set of nomens found. For example:

- Select the preferred nomen for a thema within a subject authority system to use in searching or in assigning access points: A user is using subject authority data to select "ale glasses" among the nomens "ale glasses," "glass, beer," and "malt-beverage glass" found in the Art and Architecture Thesaurus.

\section{EXPLORE: using the data in order to explore relationships between subjects and/or their appellations}

7) Using subject authority data to explore the relationships between two or more themas within the same subject authority system.

For example:

- A user is using subject authority data to explore associative relationships of the thema \{digital libraries\} and other themas.

8) Using subject authority data to explore the relationships between two or more nomens within the same subject authority system.

For example:

- A user is using subject authority data to explore the relationship of the nomen "ladybugs" and the nomen "ladybirds" in LCSH. 
9) Using subject authority data to explore the correlation of themas between two or more subject authority systems.

For example:

- A user is using subject authority data to explore the correlation of the thema \{domestic cats\} between the LCSH and the Sears List of Subject Headings.

10) Using subject authority data to explore the correlation of nomens between two or more subject authority systems.

For example:

○ A user is using subject authority data to explore whether the Medical Subject Headings (MeSH) nomen "cataract" correlates to the National Library of Medicine (NLM) Classification's nomen "WW 260."

11) Using subject authority data to explore the structure of a subject domain within a subject authority system.

For example:

- A user is using subject authority data to explore how the domain \{computer science\} is represented within the American Society for Information Science and Technology (ASIS\&T) Thesaurus.

\subsection{Mapping of Attributes, Relationships, and User Tasks}

Tables 6.1 and 6.2 map the attributes and relationships defined in chapters 4 and 5 to the defined set of user tasks. The mapping is intended to clarify which attributes and relationships are required to support each particular user task. Only attributes and relationships specified in the FRSAD model are mapped. The decision as to which attributes and relationships to include or indicate as mandatory and, to some extent, the determination of importance, are application- or implementation-specific. The degree of importance included in Table 6.1 followed the FRBR report and is based on an analysis of common library and other information agencies' practice.

\section{THEMA}

\begin{tabular}{|l|l|l|l|l|}
\hline Attributes & Find & Identify & Select & Explore \\
\hline Type of thema & $\square$ & $\square$ & $\square$ & $\square$ \\
\hline Scope note & & $\square$ & $\square$ & $\square$ \\
\hline Thema-to-Thema Relationships & $\square$ & & & \\
\hline Hierarchical relationship & $\square$ & $\square$ & $\square$ & \\
\hline Associative relationship & $\square$ & & $\square$ & $\square$ \\
\hline
\end{tabular}

Table 6.1 Mapping for Thema 


\begin{tabular}{|c|c|c|c|c|}
\hline & & & & \\
\hline Attributes & Find & Identify & Select & Explore \\
\hline Type of nomen & $\square$ & & & $\square$ \\
\hline Scheme & $\square$ & & & $\square$ \\
\hline Reference Source of nomen & & & & \\
\hline Representation of nomen & & & & $\square$ \\
\hline Language of nomen & & & & L \\
\hline Script of nomen & $\square$ & & & \\
\hline Script conversion & $\square$ & L & & \\
\hline Form of nomen & $\square$ & E & & $\square$ \\
\hline Time of validity of nomen & $\square$ & $\square$ & & $\square$ \\
\hline Audience & $\square$ & $\square$ & & \\
\hline Status of nomen & $\square$ & $\square$ & & \\
\hline Nomen-to-Nomen Relationshi & & & & \\
\hline Equivalence relationship & 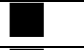 & 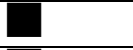 & & \\
\hline Whole-part relationship & 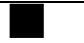 & $\square$ & & \\
\hline
\end{tabular}

Table 6.2 Mapping for Nomen

\section{CONCLUSION}

In this report, the FRSAR Working Group has presented a conceptual model within the FRBR framework as it relates to the aboutness of works. The report defines a structured frame of reference for relating the data that are recorded in subject authority records to the needs of the users of these data. The FRSAD model is developed with the goal of assisting in an assessment of the potential for international sharing and use of subject authority data both within the library sector and beyond. It enhances consideration for the functional requirements for subject authority data at a level that is independent of any implementation, system, or specific context. 